\title{
Hypoplastic left heart syndrome
}

INSERM

\section{Source}

INSERM. (1999). Orphanet: an online rare disease and orphan drug data base.

Hypoplastic left heart syndrome. ORPHA:2248

Hypoplastic left heart syndrome (HLHS) refers to the abnormal development of the leftsided cardiac structures, resulting in obstruction to blood flow from the left ventricular outflow tract. In addition, the syndrome includes underdevelopment of the left ventricle, aorta, and aortic arch, as well as mitral atresia or stenosis. 